\title{
The effect of steel fiber on some mechanical properties of self compacting concrete
}

\author{
Abbas AL-Ameeri \\ Civil, Engineering/ University of Babylon, Babylon City, Iraq
}

Email address:

abb68abb21@yahoo.com

\section{To cite this article:}

Abbas AL-Ameeri. The Effect of Steel Fiber on Some Mechanical Properties of Self Compacting Concrete. American Journal of Civil Engineering. Vol. 1, No. 3, 2013, pp. 102-110. doi: 10.11648/j.ajce.20130103.14

\begin{abstract}
Self compacting concrete (SCC) is compacting itself alone due to its self-weight and is filled almost completely while flowing in the formwork. In structural members with high percentage of reinforcement, it fills also completely all voids and gaps. The purpose of presented research is to investigate, the fresh properties of Steel Fiber SCC and the hardened properties. Fresh properties comprising flow ability, passing ability, and viscosity related segregation resistance. Hardened properties comprising compressive strength, splitting tensile strength, flexural strength, modulus of elasticity, and Ultrasonic pulse velocity. The results indicated of the fresh properties of SCC with steel fiber, reduction in workability with increase of steel fiber content. Also the Steel fibers had effect on compressive \& tensile strength , modulus of elasticity and ultrasonic pulse velocity of steel fiber self compacting concrete, there was an optimum content of steel fiber at which higher performance obtained at the both mentioned characteristics , the content was $(0.75-1) \%$. All fiber mixes demonstrated higher splitting tensile strength, and flexural strength relative to plain mix at all curing ages. The strengths increased as the fiber content increased. The fibers slightly decrease the U.P.V followed the same behavior as in compressive strength of SCC.
\end{abstract}

Keywords: Steel Fiber, Compressive Strength, Tensile Strength, Flexural Strength, Modulus of Elasticity

\section{Introduction}

The Self compacting concrete (SCC) is a concrete which has the ability to flow by its own weight and achieve good compaction without external vibration. In addition, SCC has good resistance to segregation and bleeding because of its cohesive properties [1]. The raw material selection is an important part of the mix design process for SCC, since it will significantly influence the stability as well as the cost of the mix, which are two key elements in the successful use of SCC.

There is no standard method for SCC mix design ,but many academic institutions, admixture ready-mix, precast and contracting companies have developed their own mix proportioning methods. Mix designs often use volume as a key parameter because of the importance of the need to over fill the voids between the aggregate particles. Some methods try to fit available constituents to an optimized grading envelope (European Project Group, 2005) [2]. Mix designs of SCC must satisfy the criteria on filling ability, passing ability and segregation resistance. The most common method of mix design is the general method developed by the University of Tokyo and since then, many attempts have been made to modify this method to suit local conditions [3] .In general, the following rules should be followed to be successful in manufacturing SCC, with certain methods are used [4],there are many methods for design of mixes such as Rational methods [5],and EFNARC methods [2].

SCC is known to be brittle and can easily crack under low levels of tensile force. Inherently Plain, unreinforced concrete is a brittle material, with a low tensile load and a low strain capacity. This behavior of brittleness can be overcome by using randomly oriented short discrete fibers. Fibers not only suppress the formation of cracks, but also abate their propagation and growth. Fibers have been added to hardened state.

Fiber reinforced concrete becomes an option whenever durability (limited crack widths) or safety considerations are design criteria. They improve the performance (strength and toughness) of brittle cement-based materials by bridging cracks, transmitting stress across a crack and counteracting the crack growth [6].The steel fiber is the most common fiber type in the building industry; plastic, glass and carbon fibers contribute to a smaller part to the market [7]. There are various types of steel fibers such as wave cut, end large steel fiber, deformed sheet and also hooked end steel fiber. In 
general, hooked end steel fibers are widely used in the fiber reinforced concrete because it has higher strengthening effect on the cement matrix as compared with other types of steel fibers [8] .Merging steel fibers with SCC to produce steel fiber reinforced self-compacting concrete (SFSCC) is ,therefore, highly desirable and carries a lot of potential for the concrete industry. SFSCC is an innovative type of concrete, which combines the advantages and extends the possibilities of both SCC and steel fiber reinforced concrete, dependent on the type and the content of the fibers, the workability of SCC can be significantly affected[9].

In conventional concrete, Steel fibers have been applied to replace bar reinforcement, to decrease the width of cracks, to increase tensile and flexural strength, and to improve the post-cracking behavior. Steel fiber reinforcement influences the way cracks develop in concrete and may impart improved crack growth resistance, increased surface roughness of individual cracks, and a greater likelihood for crack branching and multiple crack development. Due to this, steel fiber reinforcement may be used to significantly reduce the permeability of concrete, thus improve the durability [10].

With regard to workability, the main parameters affecting it are the fiber shape, the aspect ratio, the fiber length and the volume of fibers per $\mathrm{m}^{3}$ of concrete. Generally the same parameters which decrease the workability conversely increase the performance. Therefore it is important to find a compromise between workability and performance [11] . Steel Fibers need to be homogeneously distributed and clustering of fibers must be counteracted in order to optimize the performance of the fiber. The critical fiber content is surpassed when a stiff structure of the granular skeleton makes flow under concretes' own weight impossible [12] [13]. In principle, the properties of the fresh self-compacting concretes should not be different from conventional concrete. Only one exception is regarding the consistency. SCC is generally distinguished by their special fresh concrete properties[14]. The workability of SCC is higher than the highest class of consistence described for conventional concrete and can be characterized by Filling ability, Passing ability and Segregation resistance (European Project Group, 2005) [2]. Fibers affect hardened properties in different rates, fibers have little effect on compressive strength, a moderate on splitting tensile strength but they are generally found to have much greater effect on the flexural strength of SFRC.

Steel fibers do not have the significant influence on the compressive behavior of concrete due to the small volume of fibers in concrete mix[15].

Maidl, 1995[16]; König \& Kützing, 1999[17]; Sato et al., $2000[18]$ found that the addition of the steel fibers has hardly any effect on the compressive strength just as on the tensile strength. The ductility increases due to the addition of the fibers.

In Iraq, almost searcher are used lime stone powder as a powder in SCC mixes with cement, the lime stone powder is inactive material [19], with similar activity as aggregate but it has finer than the fine aggregate .The using this materials may be change of the properties of SCC. From this point is carried out this study to evaluate of performance of SCC with different steel fiber content at fresh and harden states .

For a newly developing material like self compacting concrete reinforced by steel fiber, studies on durability are of paramount importance for instilling confidence among the engineers and builders.

\section{Experimental Works}

\subsection{Materials Used}

\subsubsection{Cement}

Ordinary Portland cement, which has specific gravity of 3.15 and the $\mathrm{SO}_{3}$ of $2.6 \%$, was used in this investigation. It is conforming to IQS:5 -1984[20].

\subsubsection{Coarse Aggregate}

Rounded shape aggregate of MAS $10 \mathrm{~mm}$ was used and it has the following properties: Specific gravity of 2.6 and the $\mathrm{SO}_{3}$ of $0.07 \%$.

\subsubsection{Fine Aggregate}

Natural sand conforming to zone III of IQS: 45 - 1984[21] was used and its properties are found as follows: Specific gravity 2.57 and the $\mathrm{SO}_{3}$ of $0.4 \%$.

\subsubsection{Water \&Super-Plasticizer}

The drinking tap water has been used for both mixing and curing of concrete. A chemical admixture based on modified polycarboxylic ether, which is known commercially (Glenium 51) was used in producing SCC as a superplasticizer admixture. It was complied with (IQS No.1431-89)[22] and (ASTM C494-05)[23] type F .

\subsubsection{Lime Stone Powder (LSP)}

This material was used to increase the amount of powder (cement + filler). It has $\mathrm{SO}_{3}$ of $1.9 \%$ and its specific gravity was 2.8 .

\subsubsection{Fibers}

In this work, steel fiber having geometry of cylindrical with hooked ends was used. The characteristics of the steel fiber; length, diameter,t ensile strength, specific gravity were $30 \mathrm{~mm}, 0.5 \mathrm{~mm}, 1100 \mathrm{MPa}$ and 7 respectively. It was complied with (ASTM A820M-11)[24].

\subsection{Methodology}

Table 1. Proportions of reference plain mixture

\begin{tabular}{cccccccc}
\hline $\begin{array}{c}\text { Cement } \\
\mathrm{kg} / \mathrm{m}^{3}\end{array}$ & $\begin{array}{c}\text { Sand } \\
\mathrm{kg} / \mathrm{m}^{3}\end{array}$ & $\begin{array}{c}\text { Gravel } \\
\mathrm{kg} / \mathrm{m}^{3}\end{array}$ & $\begin{array}{c}\text { LSP } \\
\mathrm{kg} / \mathrm{m}^{3}\end{array}$ & $\begin{array}{c}\mathrm{SP} \\
\mathrm{L} / \mathrm{m}^{3}\end{array}$ & $\begin{array}{c}\text { Water } \\
\mathrm{L} / \mathrm{m}^{3}\end{array}$ & w/c & w/p \\
\hline 430 & 840 & 675 & 130 & 4.5 & 210 & 0.49 & 0.32 \\
\hline
\end{tabular}

The mix design method used in the present study was according to( EFNARC 2005) [2]. Table (1) shows the proportions of reference plain mixture. 
Fibers were added in quantities ranging from 0 to $1.5 \%$ by volume of total mixture. Fibers were fed into mixer by hand to ensure that clumping and clustering effects were minimized. Fiber content in FRSCC mixtures are detailed in Table (2):

Table 2. Fiber content in FRSCC mixture

\begin{tabular}{ll}
\hline Mix Symbol & Fiber Content by (Vol.\%) \\
\hline SF1 & Reference mix without fiber \\
SF2 & $0.5 \%$ steel hooked end hard-drawn wire fiber \\
SF3 & $0.75 \%$ steel hooked end hard-drawn wire fiber \\
SF4 & $1.0 \%$ steel hooked end hard-drawn wire fiber \\
SF5 & $1.25 \%$ steel hooked end hard-drawn wire fiber \\
SF6 & $1.5 \%$ steel hooked end hard-drawn wire fiber \\
\hline
\end{tabular}

The mixing process was performed in a drum laboratory mixer of $0.05 \mathrm{~m} 3$ to mix concrete ingredients. For SCC mixes which require no compaction work, the mixes being poured into the tight steel molds until its fully filled without any compaction. All specimens were demoulded after 24 hours and initial curing in tap water was performed. The curing time was for three ages $(7,28$ and 90$)$ days, until the specimens are tested.

\subsection{Fresh Concrete Tests}

The mix design were tested by more than one method for the different workability parameters. Slump flow,T500, L-box and V-funnel test were used for assessment of fresh properties of SCC in this study.

The fresh properties of plain SCC and SCC reinforced by steel fiber were tested by the procedures of (European Guidelines for self compacting concrete) [2] .

\subsection{Hardened Concrete Tests}

The mechanical properties studied are compressive strength, splitting tensile strength, flexural strength and static modulus of elasticity. Furthermore, the non-destructive test methods, Ultra-sonic pulse velocity test and Schmidt hammer test are used. The compressive strength test was performed in accordance with IQS:348-1992 [25] using $150 \mathrm{~mm}$ cube specimens. The splitting tensile strength test was carried out according to IQS:283-1995 [26] using Ø100 × $200 \mathrm{~mm}$ cylinder specimens. The test procedure given in IQS:291-1991 [27] was used to determine the flexural strength using $100 \times 100$ $\times 400 \mathrm{~mm}$ prisms. The static modulus of elasticity was performed according to IQS:370-1993 [28] by using test cylinders of $\varnothing 150 \times 300 \mathrm{~mm}$. The Utrasonic Pulse Velocity test was conducted according to IQS:300-1993 [29] by using $150 \mathrm{~mm}$ cube specimens.

\section{Results and Discussions}

\subsection{The Effect of Steel Fiber on the Fresh Properties of Self-Compacting Concrete}

\subsubsection{Slump Flow and T500 $\mathrm{mm}$}

The flowing ability of fresh concrete is described by slump flow investigated with Abrams cone. Table (3) and Figure (1) show the results of slump flow tests . The values of (D) represent the maximum spread (slump flow final diameter). All the mixtures had a slump flow diameter between (550-750) $\mathrm{mm}$. Significant decrease in slump flow diameter has been observed with incorporating steel fibers in SCC mixes, adding steel fibers increases the resistance to flow and reduces the flowability due to increasing the interlocking and friction between fibers and aggregate [30] . The decrease in slump flow was found to be increase with the increase in steel fiber content. This is likely due to the effect of the higher number of steel fibers as well as higher internal resistance of the steel fibers in fresh concrete mixtures [31]

Table 3. Results of fresh concrete tests

\begin{tabular}{lccccc}
\hline Mix & $\begin{array}{c}\text { Steel Fiber } \\
(\% \text { by Vol. })\end{array}$ & $\begin{array}{c}\mathrm{D} \\
(\mathrm{mm})\end{array}$ & $\begin{array}{c}\mathrm{T}_{500} \\
(\mathrm{Sec})\end{array}$ & $\begin{array}{c}\text { Blocking } \\
\text { Ratio }(\mathrm{BR})\end{array}$ & $\begin{array}{c}\mathrm{T} \mathbf{v} \\
(\mathrm{sec})\end{array}$ \\
\hline SF1 & 0 & 750 & 2.1 & 0.97 & 6.6 \\
SF2 & 0.5 & 720 & 2.28 & 0.94 & 7.0 \\
SF3 & 0.75 & 680 & 2.95 & 0.90 & 7.7 \\
SF4 & 1 & 670 & 3.14 & 0.85 & 8.3 \\
SF5 & 1.25 & 625 & 3.65 & 0.82 & 8.8 \\
SF1 & 1.5 & 584 & 4.25 & 0.8 & 9.3 \\
\hline
\end{tabular}

While the values of $\mathrm{T} 500 \mathrm{~mm}$ represent the time required for the concrete flow to reach the $500 \mathrm{~mm}$ diameter during the slump flow test was also measured and recorded as T500 (sec) (Slump Flow Time), which indicates the speed of flow and hence the viscosity of the self-compacting concrete. Table (3) and Figure (2) show the results of T500mm . The values were ranged between $(2.1-4.25) \mathrm{sec}$. According to the (European Project Group, 2005) [2], SCC can be classified as VS1 for $\mathrm{T} 500 \leq 2 \mathrm{sec}$ or VS2 for T500 $>2 \mathrm{sec}$.

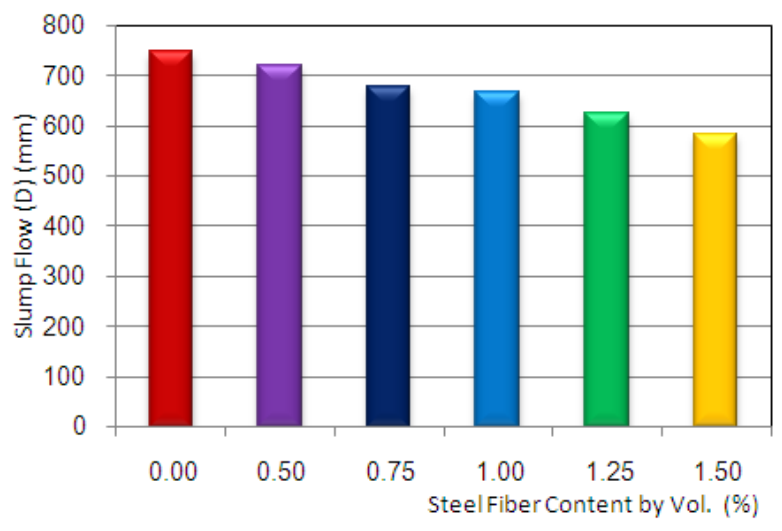

Figure 1. Effect of steel fiber content on Slump Flow Test of SCC

Including steel fiber in SCC mixtures resulted in an increase in T500 values. The increase of percentages found to be increase with the increase in fiber content. The increasing of slump time due to increase of internal friction resultant from higher number of steel fiber.All results of 
slump flow and slump flow time were conformed EFNARC 2005 limitations.

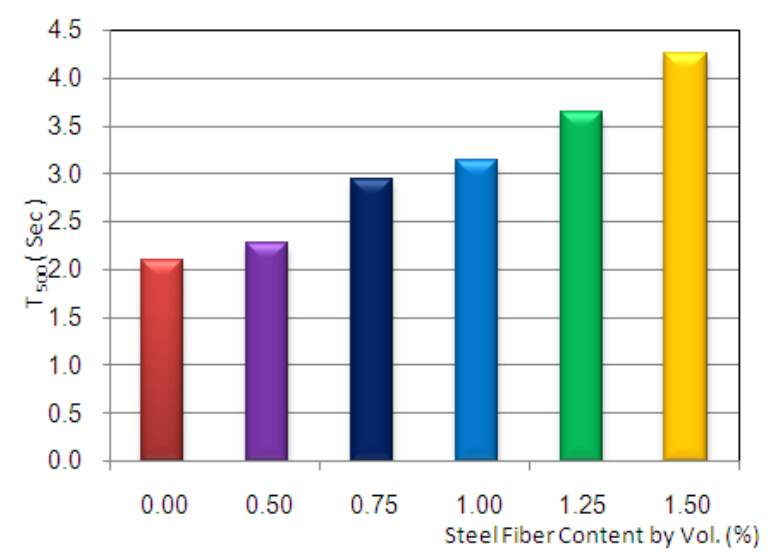

Figure 2. Effect of steel fiber content on $T_{500}$ Test of SCC

\subsubsection{L-Box Passing Ability}

The L-Box with 2 bars was used in this study to assess the passing ability of the mixes. The Blocking Ratios results $(\mathrm{BR}=\mathrm{H} 2 / \mathrm{H} 1)$ of the tests are summarized in Table (3) \& plotted in Figure(3). The results of the BR ranged between $(0.8-0.97)$. The results show that the BR decreased with increasing steel fiber content. The higher the steel fiber content, the lower the BR was.

Introducing steel fibers had its impact on passing ability. The decreased of the BR with increasing steel fiber content due to internal resistance of flow of concrete result of increasing of number of steel fiber [32].

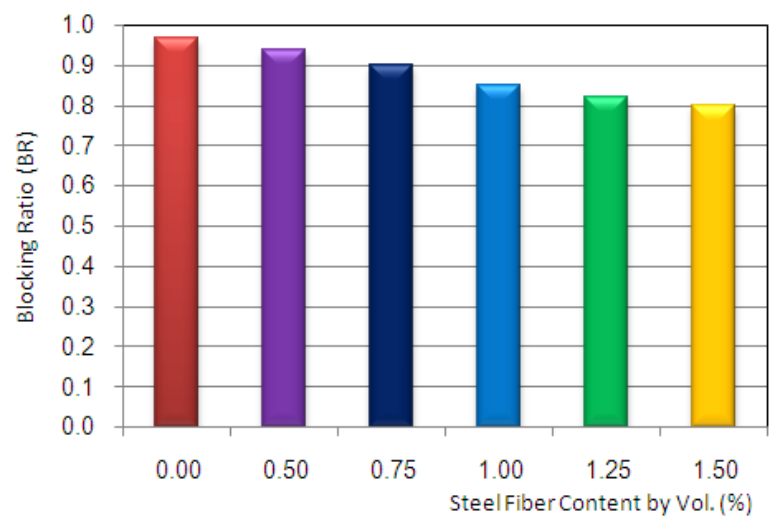

Figure 3. Effect of steel fiber content on Blocking Ratio Test of SCC

\subsubsection{V-Funnel Flow Time}

The V-funnel test is used to assess the viscosity and filling ability of self-compacting concrete [2]. Table (3) shows the results of $\mathrm{V}$-funnel test. The $\mathrm{TV}$ values ranged between(6.6-9.3) sec. SCC is classified into two categories: VF1 ( $\leq 8 \mathrm{sec})$ and VF2 (9-25) sec (European Project Group, 2005).

The results fall in VF1 and VF2 categories, referring to that the mixes have moderate to relatively high viscosity, indicating reduced filling ability and at the same time ameliorated segregation resistance.

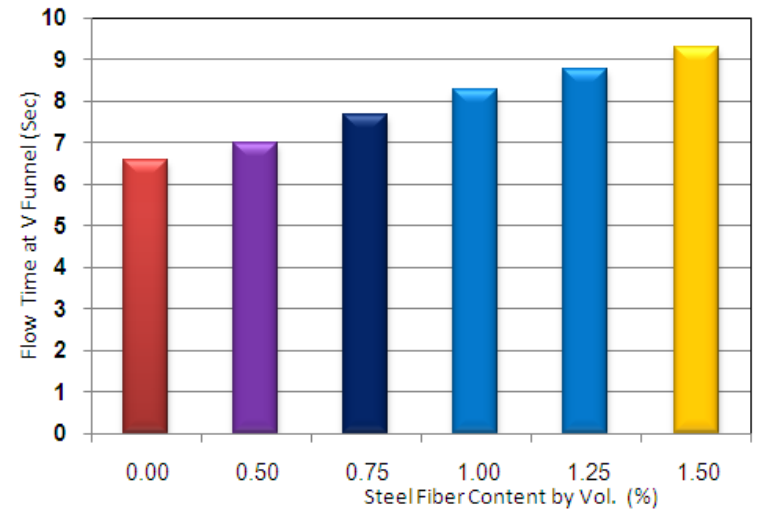

Figure 4. Effect of Steel Fiber Content on Flow Time at V Funnel $\left(T_{V}\right)$ Test of SCC

V-Funnel flow time increased by incorporating steel fibers in mixes as illustrated in Fig.(4). Similar behavior was observed in the T500 test. Besides, the higher the steel fiber content, the higher the flow-time. This can be ascribed to, the increasing in fiber content leads to increase the friction between the fibers and aggregates and the friction of the fibers with each other which could extend the required time to empty the V-funnel [33].

\subsection{The Effect of Steel Fiber on Hardened Properties of SCC}

\subsubsection{Compressive Strength}

The compressive strength, is one of the most important properties of hardened concrete .Table (4) and Figure(5) show the average of the results of The compressive strength test at 7, 28and 90 days. The results indicate that all specimens exhibited a continuous increase in compressive strength with progress in age. This increase in compressive strength with age is due to the continuity of hydration process which forms a new hydration product within the concrete mass [34].Also the results indicate to compressive strength of the SCCs increases by steel fiber introduction, the compressive strength increases as the steel fiber volume increases up to $0.75 \%$ beyond, the compressive strength decreases ,however, it still higher than the plain SCC as illustrated in Figure(6). The percentage of changes (increase ) in compressive strength for all mixes with steel fiber content are represented in Table (4).

The increase in compressive strength may be associated with uniform dispersion of fine fibers throughout self-compacting concrete of high flowability, leading to consistent internal integrity. Also this improvement in the compressive strengths of the steel fiber reinforced SCC refer to the control of cracking and the mode of failure by means of post cracking ductility. However, steel fibers caused crack closing forces which led to increase the compressive strength. While, fiber addition caused the increase of entrapped air which decreased the compressive strength. Both effects in combination had the tendency to a little increase in compressive strength especially in SCC mixes reinforced with fibers higher than $0.75 \%$. therefore, the steel 
fibers could increase the compressive strength only if it does not change, to a certain limit, the air content [30].

Table 4. Results of Compressive strength test of scc

\begin{tabular}{|c|c|c|c|c|c|c|}
\hline \multirow[t]{2}{*}{ Mix } & \multicolumn{3}{|c|}{$\begin{array}{l}\text { Compressive } \\
\text { Strength(MPa) }\end{array}$} & \multicolumn{3}{|c|}{$\begin{array}{l}\text { Change in Compressive } \\
\text { strength with respect to reference } \\
\text { mix (SF1) \% }\end{array}$} \\
\hline & $\begin{array}{l}7 \\
\text { days }\end{array}$ & 28days & 90days & 7 days & 28 days & 90 days \\
\hline SF1 & 27.5 & 35.4 & 45.1 & - & - & - \\
\hline SF2 & 30.4 & 37.6 & 47.2 & 10.55 & 6.21 & 4.66 \\
\hline SF3 & 35.6 & 45.2 & 48.3 & 29.45 & 27.68 & 7.10 \\
\hline SF4 & 34.5 & 43.2 & 47.2 & 25.45 & 22.03 & 4.66 \\
\hline SF5 & 33.3 & 42.5 & 46.5 & 21.09 & 20.06 & 3.10 \\
\hline SF6 & 33.1 & 42.1 & 46.0 & 20.36 & 18.93 & 2.00 \\
\hline
\end{tabular}

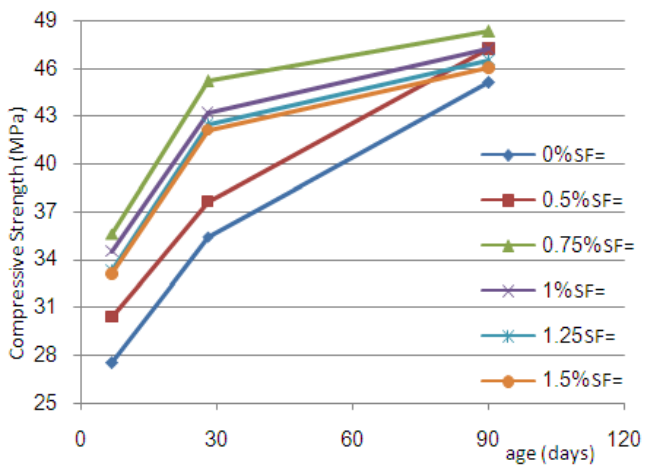

Figure5. Development of compressive strength with age for different $S F$ content in SCC

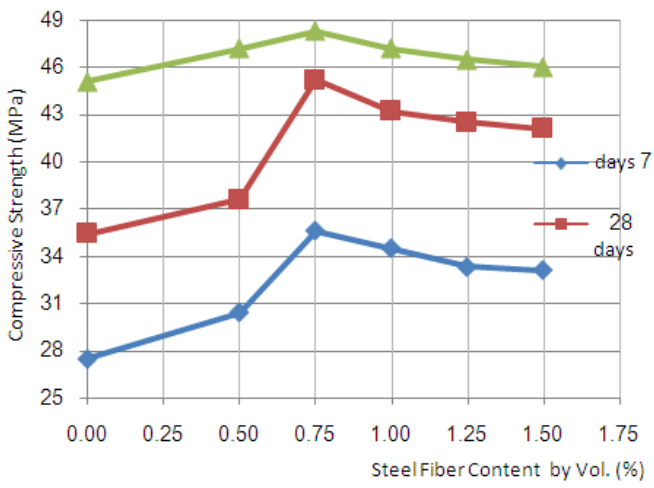

Figure 6. Effect of SF content on compressive strength in SCC at age (7,28and 90) days

\subsubsection{Splitting Tensile Strength}

The results splitting tensile strength indicate that all specimens exhibited a continuous increase in splitting tensile strength with progress in age as summarized in Table (5) and Fig.(7).Also, the results observed that splitting tensile strength of the SCCs increases with steel fiber content. The splitting tensile strength increases with increasing in steel fiber volume up to $1.5 \%$. Also the percentage of increase in splitting tensile strength are listed in Table (5) and illustrated in Fig (8).

The strength increase due to inclusion of steel fibers is attributed to the mechanism of steel fibers in arresting crack progression. Where, the presence of fibers in concrete restrains the development of internal microcracks and thus contributes to an increased tensile strength. Accordingly, the increase in fiber content leads to an increase in the tensile strength of concrete. Moreover, the improved bonding of fiber-matrix that provided by the shape of the steel fiber, hooked ends, boosted pullout strength and thus, yielded high increment in strength due to inclusion of fibers [7] [35].

Table 5.Results of Spitting Tensile strength test of SCC

\begin{tabular}{|c|c|c|c|c|c|c|}
\hline \multirow[t]{2}{*}{ Mix } & \multicolumn{3}{|c|}{$\begin{array}{l}\text { Spitting Tensile Strength Test } \\
\text { (MPa) }\end{array}$} & \multicolumn{3}{|c|}{$\begin{array}{c}\text { Change in Spitting Tensile } \\
\text { strength with respect to } \\
\text { reference mix (SF1) \% }\end{array}$} \\
\hline & 7 days & 28 days & 90 days & 7 days & 28 days & 90 days \\
\hline SF1 & 3.0 & 3.7 & 4.25 & - & - & - \\
\hline SF2 & 3.7 & 4.3 & 5 & 23.33 & 16.22 & 17.65 \\
\hline SF3 & 4.6 & 5.0 & 5.5 & 53.33 & 35.14 & 29.41 \\
\hline SF4 & 4.7 & 5.3 & 6.0 & 56.67 & 43.24 & 41.18 \\
\hline SF5 & 4.9 & 5.4 & 6.5 & 63.33 & 45.95 & 52.94 \\
\hline SF6 & 5.0 & 5.5 & 6.5 & 66.67 & 48.65 & 52.94 \\
\hline
\end{tabular}

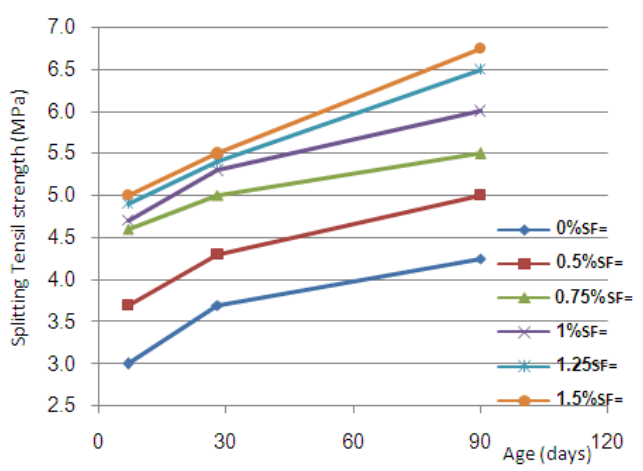

Figure 7. Development of splitting tensile strength with age for different SF content in SCC

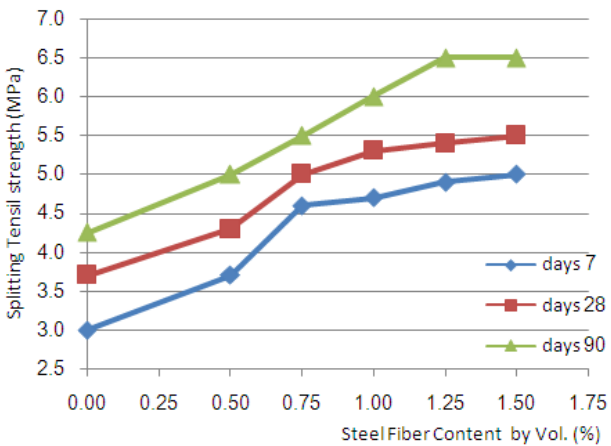

Figure 8. Effect of SF content on splitting tensile strength in SCC at age $(7,28$ and 90$)$ days

\subsubsection{Flexural Strength}

Similar to splitting tensile strengths of concrete, the results indicate that all specimens exhibited a continuous increase in flexural strength with progress in age as shown in Table (6) and Figure(9) .The results indicated to the effect of steel fiber on flexural tensile strength of the SCCs was very clearly, and they showed the benefit of steel fibers to improve of flexural strength, This improvement in flexural strength increases with the increase in steel fiber volume up to $1.5 \%$ 
The flexural strength indicated significant increase in strength due to the inclusion of steel fibers. The percentages of increase in flexural tensile strength for all mixes are summarized in Table (6) and illustrated in Figure(10).

The flexural strength increases, due to the superior performance in flexural strength for specimens with steel fibers arises from the improved fiber - matrix bond provided by using steel fiber with hooked ends [36] .

Also, the percentage of increasinge in flexural strength was found to be increased with the increase in steel fiber content. This behavior is mainly attributed to the role of steel fibers in releasing fracture energy around crack tips which is required to extent crack growing by transferring it from one side to another side [37].

Table 6. Results of Flexural Tensile strength test of SCC

\begin{tabular}{|c|c|c|c|c|c|c|}
\hline \multirow[t]{2}{*}{ Mix } & \multicolumn{3}{|c|}{$\begin{array}{c}\text { Flexural Tensile Strength } \\
\text { Test(MPa) }\end{array}$} & \multicolumn{3}{|c|}{$\begin{array}{l}\text { Change in Flexural strength } \\
\text { with respect to reference mix } \\
\text { (SF1) \% }\end{array}$} \\
\hline & 7 days & 28 days & 90 days & 7 days & 28 days & 90 days \\
\hline SF1 & 5.1 & 5.5 & 6.5 & - & - & - \\
\hline SF2 & 6.9 & 7.5 & 8 & 35.29 & 36.36 & 23.08 \\
\hline SF3 & 7.7 & 8.5 & 9 & 50.98 & 54.55 & 38.46 \\
\hline SF4 & 8.5 & 9.5 & 10.5 & 66.67 & 72.73 & 61.54 \\
\hline SF5 & 8.7 & 10.5 & 11.3 & 70.59 & 90.91 & 73.85 \\
\hline SF6 & 9 & 11 & 11.5 & 76.47 & 100.00 & 76.92 \\
\hline
\end{tabular}

When the tensile stress is transferred to fibers, the transfer can arrest the propagating macro-cracks and substantially improve. Crack control plays a crucial role in the performance of concrete in service. The loads may overstress hardened concrete from cracking, leading from cracking to substantial failure in concrete. Thus, incorporation of discrete fibers in vulnerable concrete is useful and effective. The resulting fiber-reinforced concrete exhibits satisfactory resistance to crack formation and propagation [7].

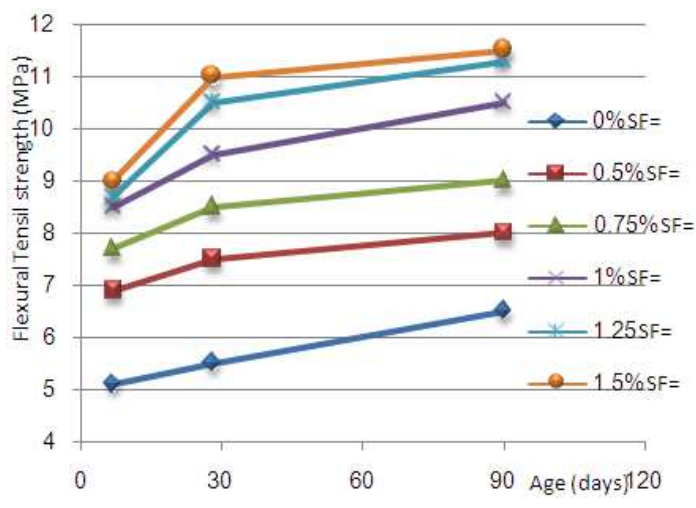

Figure 9. Development of Flexural tensile strength with age for different $S F$ content in $S C C$

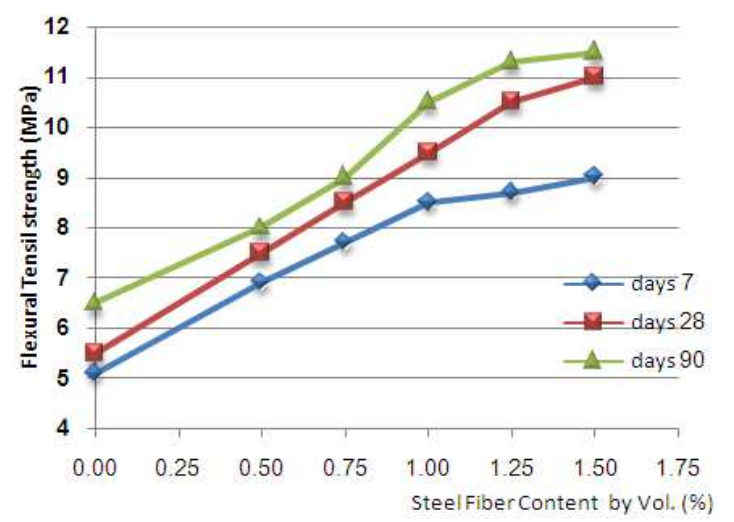

Fig (10). Effect of SF content on Flexural tensile strength in SCC at age (7,28and 90) days

\subsubsection{Modulus of Elasticity}

The static modulus of elasticity for all mixes is experimentally determined at ages 28 and 90 days, the results of this test are listed in Table (7). The results listed in Table (6) and plotted in Fig.(11)show steel fibers demonstrated similar impact on elastic modulus as on compressive strength. However, the increments due to incorporating steel fibers were insignificant, the percentages of change in elastic modulus for SCCs are listed in Table (7) and plotted in Fig.(12) Since, the main role provided by steel fiber starting after the concrete suffering plastic deformation, thus, steel fiber would not contribute much to elastic deformation stage [38] [39] .

Table 7.Results of Modulus of Elasticity test of SCC

\begin{tabular}{ccccc}
\hline & \multicolumn{2}{c}{$\begin{array}{c}\text { Modulus of Elasticity } \\
\text { Test }(\mathrm{GPa})\end{array}$} & \multicolumn{2}{c}{$\begin{array}{c}\text { Change in Modulus of } \\
\text { Elasticity with respect to } \\
\text { reference mix (SF1) } \%\end{array}$} \\
\cline { 2 - 5 } & 28 days & 90 days & 28 days & 90 days \\
\hline SF1 & 24.5 & 27 & - & - \\
SF2 & 26 & 27.5 & 6.12 & 1.85 \\
SF3 & 27.2 & 28 & 11.02 & 3.70 \\
SF5 & 27.3 & 29 & 11.43 & 7.41 \\
SF5 & 27.1 & 28.5 & 10.61 & 5.56 \\
SF6 & 27 & 27.9 & 10.20 & 3.33 \\
\hline
\end{tabular}

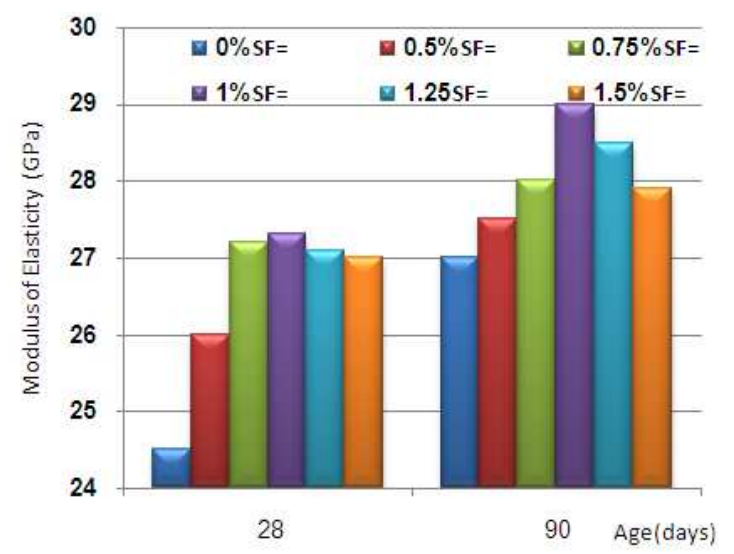

Figure 11. Development of Modulus of Elasticity with age for different SF content in SCC 


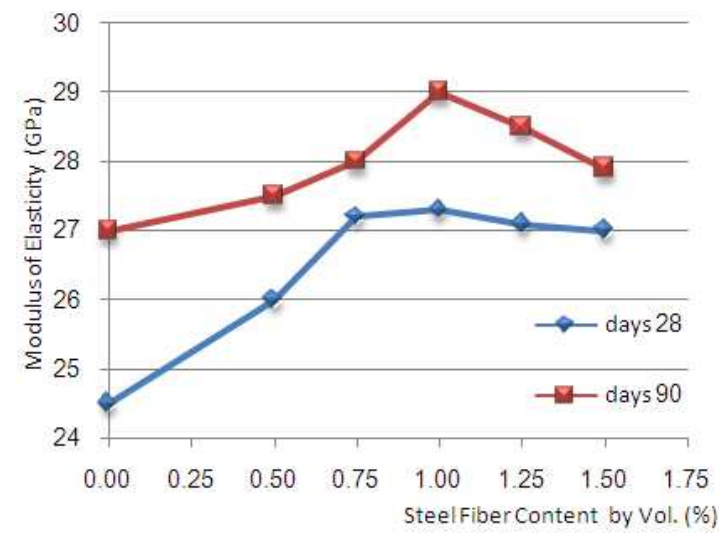

Figure 12. Effect of SF content on Modulus of Elasticity in SCC at age (7,28and 90) days

\subsubsection{Ultra-Sonic Pulse Velocity}

Ultrasonic pulse velocity increased with the increase in curing age of SCC mixes. The results of ultrasonic pulse velocity for the various types of SCC mixes at $(7,28$ and 90 days) are presented in Table (8) and Figure (13). It can be seen that introducing steel fibers negatively affected the ultrasonic pulse velocity as shown in Table (8) and Figure(14). This might be attributed to the increase of the amount of entrapped air voids due to incorporation of fibers into the mixes. besides, the fibers inside cube were randomly oriented, when the wave pass through the fibers the wave maybe deflected to other directions rather than pass straight forward to the end of the cube [35].

Table 8. Results of Ultra-sonic Pulse velocity test of SCC

\begin{tabular}{|c|c|c|c|c|c|c|}
\hline \multirow[t]{2}{*}{ Mix } & \multicolumn{3}{|c|}{$\begin{array}{l}\text { Ultra-sonic Pulse velocity } \\
\text { Test }(\mathrm{km} / \mathrm{sec})\end{array}$} & \multicolumn{3}{|c|}{$\begin{array}{l}\text { Change in Ultra-sonic Pulse } \\
\text { velocity with respect to } \\
\text { reference mix (SF1) \% }\end{array}$} \\
\hline & 7 days & 28 days & 90 days & 7 days & 28 days & 90 days \\
\hline SF1 & 4.3 & 4.4 & 4.6 & - & - & - \\
\hline SF2 & 4.1 & 4.3 & 4.5 & -4.65 & -2.27 & -2.17 \\
\hline SF3 & 3.8 & 4.2 & 4.4 & -11.63 & -4.55 & -4.35 \\
\hline SF4 & 3.6 & 4.1 & 4.3 & -16.28 & -6.82 & -6.52 \\
\hline SF5 & 3.5 & 4.1 & 4.2 & -18.60 & -6.82 & -8.70 \\
\hline SF6 & 3.4 & 4 & 4.1 & -20.93 & -9.09 & -10.87 \\
\hline
\end{tabular}

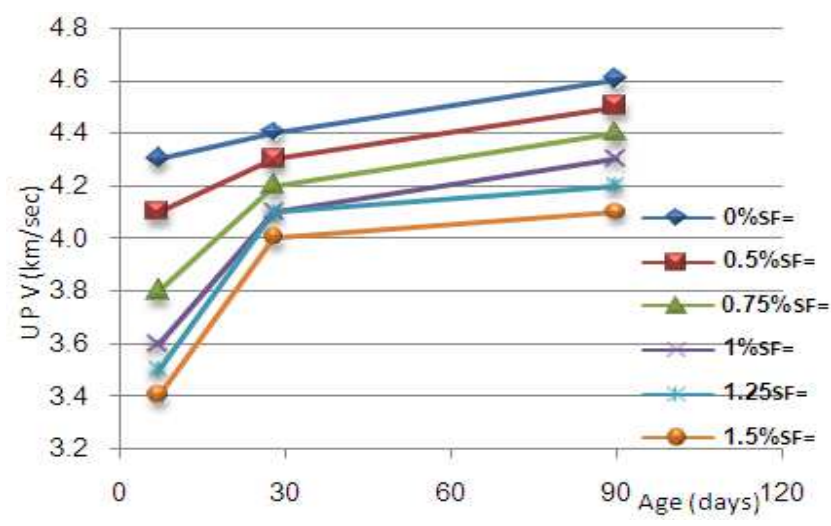

Figure 13. Development of Ultra-sonic Pulse velocity with age for different SF content in SCC

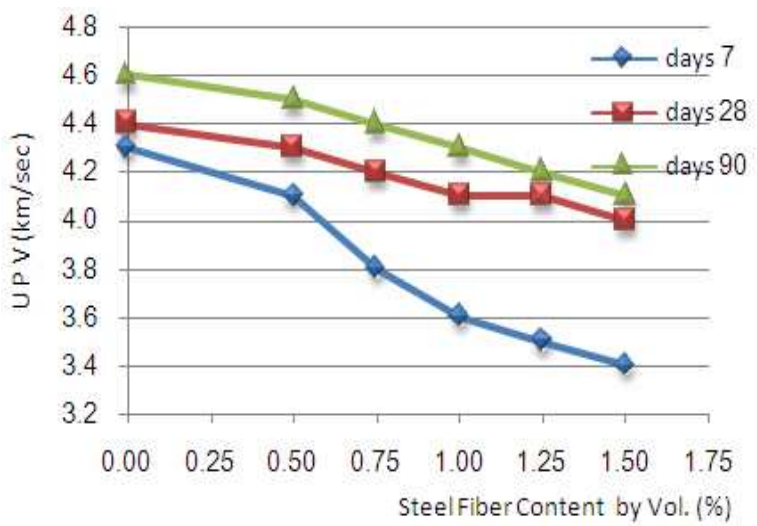

Figure 14. Effect of SF content on Ultra-sonic Pulse velocity in SCC at age $(7,28$ and 90$)$ days

\section{Conclusions}

1. Overall, slump flow diameter (flowability) and L-Box blocking ratios (passing ability) decrease with the increase in steel fiber content of the concrete mixtures with respect to plain mixtures. However, all mixes are satisfied to SCC requirements.

2. Slump flow time and V-funnel flow time increase with the increase in steel fiber content of the concrete mixtures with respect to plain mixtures.

3. Steel fibers increased in compressive strength and modulus of elasticity at early age, but at age 90 days, steel fibers had a marginal increments in compressive strength and modulus of elasticity compared to the increments in the other mechanical properties.

4. All steel fiber mixes demonstrated a higher splitting tensile strength and flexural strength relative to plain mixes at all curing ages. The tensile strength increased as the fiber content increased, however, the increments in flexural strength were higher than splitting tensile strength with more than $90 \%$ increments having been recorded.

5. Ultrasonic pulse velocity decreased with including steel fiber in SCC.

6. The highest steel fiber content 1.5 (\% by Vol.) had, in general, best effect on hardened properties but the worst on fresh properties of SCC.

7. As well, $(0.75,1) \%$ steel fiber content were sufficient for achieving satisfying (optimum ) performance in fresh and hardened properties of SCC.

\section{Acknowledgements}

The authors thanks Mahoumd R.H.and Ahmed S.M. for supported him to complete this work .

\section{References}

[1] Okamura H., and Ouchi M., (2003), "Self-Compacting Concrete", Journal of Advanced Concrete Technology, Vol.1, No. 1, pp.(5-15). 
[2] European Project Group, (2005), "The European Guidelines for Self-Compacting Concrete: Specification, Production and Use", pp.63.

[3] Hodws D.W., Sheinn A.M., Ng C.C., lim W.B., and Tam C.T., (2001), "Self-compaction concrete for Singapore", 26th Conference on Our World in Concrete and Structures., 26-28 August, 2001, Singapore.

[4] Collepardi M., (2006), "Main ingredients and basic principles for SCC production”, Department of Applied Physical Chemistry, Politecnico of Milan, Italy.

[5] Okamura H., and Ozawa K., (1995), "Mix design for self-compacting concrete", Concrete Library of JSCE, No.25, pp.(107-120).

[6] Grunewald S., and Walraven J.C., (2009), "Transporting fibers as reinforcement in self-compacting concrete", HERON, Vol. 54, No. 2/3, pp.(101-126).

[7] Gencel O., Brostow W., Datashvili T., and Thedford M., (2011), "Workability and mechanical performance of steel fiber-reinforced self-compacting concrete with fly ash", Bartin University, Turkey

[8] Tadepalli P., Mo Y., Hsu T., and Vogel J., (2009), "Mechanical properties of steel fiber reinforced concrete beams", ASCE Structures Congress, pp.(1039-1048).

[9] Vikan H., (2007), "State of the art report on Concrete workability and fiber content", SINTEF Building and Infrastructure , COIN - Concrete Innovation Centre, Norway, pp.(1-38), www.sintef.no./coin

[10] ACI Committee 544.5R, (2010), "Report on the Physical Properties and Durability of Fiber-Reinforced Concrete", American Concrete Institute.

[11] Pereira E.B., Barros J.A.O., Cunha V.M., and Santos S.P.,(2005), "Compression and bending behavior of steel fiber reinforced self-compacting concrete", Portugal Civitest Company, University of Minho, Portugal

[12] Balaguru P., and Najm H., (2004), "High performance fiber-reinforced concrete mixture proportions with high fiber volume fractions", ACI Materials Journal, Vol. 101, pp.(281-286).

[13] Grunewald S., (2004), "Performance based design of self compacting fiber reinforced concrete", Ph.D. thesis, Delft University of Technology, Netherlands.

[14] Dehn F., Holschemacher K., and Weiße D., (2000), "Self-compacting concrete (SCC) time development of the material properties and the bond behavior", LACER No. 5., pp.(115-124)

[15] Armelin H.S., and Helene P., (1995), "Physical and mechanical properties of steel fiber reinforced dry-mix shotcrete" ACI Materials Journal, Vol.92, pp. (258-267).

[16] Maidl B.R., (1995), "Steel fiber reinforced concrete", Ernst \& Sohn, Berlin, ISBN: 3433012881.

[17] Konig, G., and Kutzing L., (1999), "Modelling the increase of ductility of HPC under compressive forces - a fracture mechanical approach", Proceedings of the 3rd International RILEM Workshop on High Performance Fiber Reinforced Cementitious Composites(HPFRCC 3), Reinhardt H. W. and Naaman A. E., eds, RILEM Publications SARL, Mainz,
Gernany, pp.(251-259).

[18] Sato Y.,Van Mier J.G., and Walraven J.C., (2000),"Mechanical characteristics of multi-modal fiber reinforced cement based composites", In Proceedings 5th International RILEM Symposium, Rossi p. and Chanvillard G., eds, RILEM Publications, Cachan Cedex, France, pp. (791-800).

[19] Mahmoud R.H., (2012), "Effect of sulfate on the properties on of self compacting concrete reinforced by steel fiber", M.Sc. thesis ,College of Engineering, University of Babylon.

[20] Iraqi Specification, IQS No.5/1984, "Portland cement" Central Organization for Standardization \&Quality Control COSQC, Baghdad, 2001.

[21] Iraqi Specification, IQS No.45/1984, “Aggregates from natural sources for concrete and construction" Central Organization for Standardization \&Quality Control COSQC, Baghdad, 2001.

[22] Iraqi Specification, IQS No.1431/1989, “Admixture of concrete" Central Organization for Standardization \&Quality Control COSQC, Baghdad, 2001.

[23] American Society for Testing and Materials, ASTM C 494-2005,"Standard specification for chemical admixtures for concrete," Annual Book of ASTM Standards, Vol. 04-02.

[24] American Society for Testing and Materials, ASTM A 820M-2005,"Standard specification for steel fiber for fiber-reinforced concrete," Annual Book of ASTM Standards, Vol. 04-02.

[25] Iraqi Specification, IQS No.348/1992, "Determination of compressive strength of concrete cubes," Central Organization for Standardization \&Quality Control COSQC, Baghdad, 2001.

[26] Iraqi Specification, IQS No.283/1995, "Splitting tensile strength of concrete" Central Organization for Standardization \&Quality Control COSQC, Baghdad, 2001.

[27] Iraqi Specification, IQS No.291/1991, "Modulus of rupture of concrete" Central Organization for Standardization \&Quality Control COSQC, Baghdad, 2001.

[28] Iraqi Specification, IQS No.370/1993, "Static modulus of elasticity of concrete" Central Organization for Standardization \&Quality Control COSQC, Baghdad, 2001.

[29] Iraqi Specification, IQS No.300/1993, "Pulse velocity through concrete" Central Organization for Standardization \&Quality Control COSQC, Baghdad, 2001.

[30] Al-Musawee H.A., ( 2011), "Effect of using fibers on some mechanical properties of self compacting concrete", M.Sc. thesis ,college of Engineering, University of Babylon.

[31] Ahmed S.M., (2013), "The effect of elevated temperature on the properties on of self compacting concrete reinforced by steel fiber ", M.Sc. thesis ,College of Engineering, University of Babylon.

[32] Grunewald S., and Walraven J.C., (2001), "Parameter-study on the influence of steel fibers and coarse aggregate content on the fresh properties of self-compacting concrete", Cement and Concrete Research, Vol. 31, pp.(1793-1798).

[33] Neville, A.M.,( 2010), "Properties of concrete", Longman Group Ltd.,5th Edition, pp. (329-397), (674-687). 
[34] Mon T. K., (2010),"Flexural behaviour of steel fiber reinforced concrete slab", B.Sc., College of civil Engineering, University of Technology, Malaysia.

[35] Banthia N., and Trottier J., (1994), "Concrete reinforced with deformed steel fibers, Part I: Bond-slip mechanisms", ACI Materials Journal, Vol. 91, No. 5, pp.(435-446).

[36] TengY.S.and Shah S.P.,(1986), “'Crack propagation in fiber reinforced concrete "Journal of Structure Engineering, Vol.112,1,pp(19-34).
[37] Alubaidi I.H., 2011, "Effect of curing conditions on the mechanical properties of steel fiber reinforced self compacting concrete" Al-Qadisiya Journal For Engineering Sciences, Vol. 4, No.4, pp.(528-536).

[38] Aboud A.M., (2011), "Behavior of self compacting fibrous reinforced concrete columns under transverse cyclic load", M.Sc. thesis ,College of Engineering, University of Babylon 